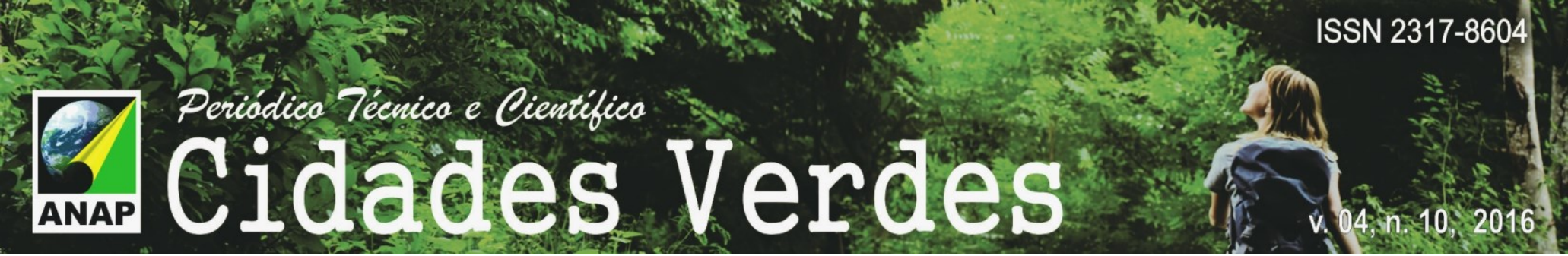

\title{
ANOTAÇÕES PARA UMA POLÍTICA URBANA DE BAIRROS ECOLÓGICOS. UM ESTUDO A PARTIR DA CIDADE DE FORTALEZA-CE
}

Any Notes for an Urban Policy of Ecological Neighborhoods. A study about the city of Fortaleza-Brazil.

Comentários para una política urbana de barrios ecologicos. Un estudio realizado en la ciudad de Fortaleza-Brasil.

José Almir Farias Filho Professor Doutor, UFC, Brasil josealmirfarias@gmail.com 


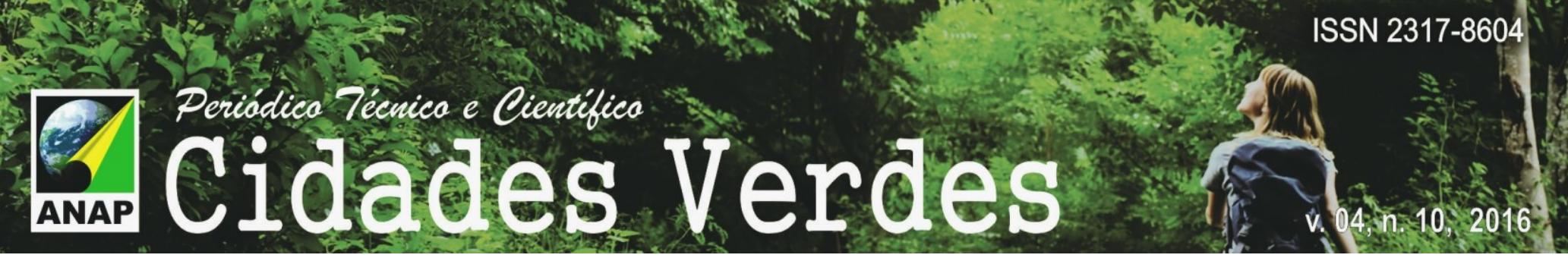

\section{RESUMO}

Este trabalho tem por objetivo destacar algumas questões prático-teóricas para uma política urbana de bairros ecológicos no Brasil, entendida como um conjunto de programas, projetos e ações destinados a transformar progressivamente os bairros ordinários de nossas cidades em bairros sustentáveis. A hipótese adotada é a de que a escala espacial do bairro traz consigo a convergência das expectativas sociais que fundamentam a produção de inovações técnicas ecológicas dando forma a uma nova consciência e representatividade de moradores e usuários. Do ponto de vista metodológico, os argumentos aqui apresentados resultam de um estudo sobre os bairros da cidade de Fortaleza-Ce, com base em dois procedimentos: a análise empírica da estruturação dos bairros da cidade e um exercício de intervenção urbanística realizado em um dos seus bairros, o Edson Queiroz. Os resultados desta investigação indicam que a institucionalização de uma política urbana de ecobairros pode fortalecer o controle social e diminuir as desigualdades intraurbanas, atuando como escala urbana de ações redistributivas.

PALAVRAS-CHAVE: Política Urbana - Ecobairro. Urbanismo Ecológico. Fortaleza-Ce.

\section{ABSTRACT}

This paper seeks to highlight some practical-theoretical issues related to the urban policy for ecological neighborhoods in Brazil which is understood as a set of programs, projects and actions aimed to the gradual transformation of ordinary neighborhoods of our cities into sustainable neighborhoods. The adopted hypothesis is that the scale of the neighborhood converges social expectations that fundament the production of ecological technical innovations and open the way to residents' awareness and representation. From a methodologial point of view, the practical component of the paper is a result of studies that were undertaken on neighborhoods of Fortaleza city. Two procedures were used: an empirical analysis of the neighborhoods structure and an urban intervention exercise in one of those neighborhoods: the Edson Queiroz. The outcomes of this investigation indicate that the institutionalization of an eco-neighborhood urban policy can strengthen social control and reduce intraurban inequalities as they can act as urban redistributive actions.

KEYWORDS: Urban Policy - Econeighborhoods. Ecological Urbanism. Fortaleza-Brazil.

\section{RESUMEN}

Este artículo tiene como objetivo extraer algunas algunas cuestiones prácticas y teóricas para una política urbana de barrios ecológicos en Brasil, entendida como un conjunto de programas, proyectos y acciones dirigidas a transformar gradualmente los barrios ordinarios de nuestras ciudades en barrios sostenibles. La hipótesis adoptada es que la escala espacial de la vecindad trae la convergencia de las expectativas sociales que subyacen a la producción de innovaciones técnicas ecológicas que configuran una nueva conciencia y representación de los residentes y usuarios. Desde un punto de vista metodológico, los argumentos aquí presentados son el resultado de un estudio de los barrios de la ciudad de Fortaleza, sobre la base de dos procedimientos: el análisis empírico de la estructura de los barrios de la ciudad y el ejercicio de intervención urbana en un de sus barrios, el Edson Queiroz. Los resultados de esta investigación indican que la institucionalización de una política urbana ecobarrios puede fortalecer el control social y reducir las desigualdades intra-urbanas, es decir, el bairro como escala urbana de acciones redistributivas.

PALABRAS-CLAVE: Política Urbana -Ecobarrio. Urbanismo ecológico. Fortaleza-Brasil. 


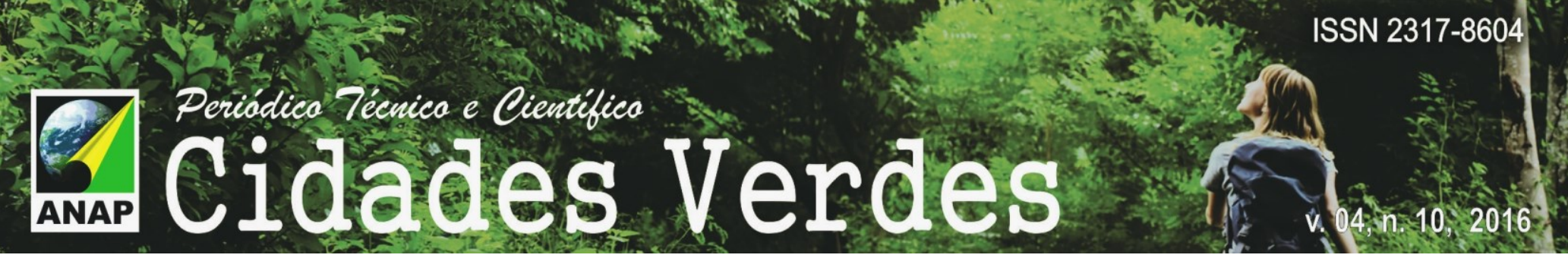

O bairro é o ponto de contato mais fortuito entre o espaço geométrico e o espaço social, o ponto de passagem de um ao outro. (HENRI LEFEBVRE, 1967).

\section{INTRODUÇÃO}

O bairro ecológico, ou ecobairro, é um capítulo relativamente recente na história das experimentações em planejamento e projetos urbanos sustentáveis. Nos diversos trabalhos que abordam essa prática, os pesquisadores concordam que o objetivo central de um ecobairro é contribuir para a coesão socioambiental, destacando o papel da infraestrutura verde, a qualidade dos espaços públicos, os processos e opções de produção de energia limpa e a importância da mudança de estilos de vida e padrões de consumo. A escolha de uma abordagem integrada e a participação dos cidadãos, tanto ao nível do planejamento como da execução, seriam elementos cruciais na concepção de ecobairros, rejeitando-se, portanto, os esquemas simplistas que comandaram os regulamentos urbanísticos dos últimos 50 anos.

A maioria das experiências precursoras de ecobairros - em especial nos países do norte europeu na última década do século XX - revela a idealização de projetos exemplares com um desenho urbano do tipo "all of a piece" para áreas centrais degradadas ou zonas periféricas. Esses projetos levavam em conta um certo número de intervenções de conteúdo social, econômico e ambiental, embora alguns analistas, como Poupinot (2011), critiquem o seu evidente elitismo social por constituírem novos guetos burgueses ecológicos com atenção excessiva à estética, negligência quanto a mistura socioeconômica e com custos operacionais pouco acessíveis às populações de baixa renda.

De fato, projetos urbanos modelares para setores específicos tendem a dificultar a sua interação com o tecido urbano pré-existente e, sobretudo, não corroboram para a solução dos problemas socioambientais na escala da cidade. Essa compreensão nos leva a pensar o ecobairro, não como uma concepção padronizada, mas como uma estratégia de ação programática aberta, adaptável e continuada dos princípios da Agenda 21 local. Dito de outro modo, como uma política pública que assimile o bairro a um só tempo como unidade ecossistêmica e como parte essencial da estruturação urbana.

Em tal perspectiva, o objetivo deste trabalho é destacar algumas questões prático-teóricas para a concepção de uma política urbana de bairros ecológicos, entendida como um conjunto de programas, projetos e ações destinados a transformar progressivamente os bairros ordinários de nossas cidades em bairros sustentáveis. A hipótese adotada é a de que a escala espacial do bairro traz consigo a convergência das expectativas sociais que fundamentam a produção de inovações técnicas ecológicas dando forma a uma nova consciência e representatividade de moradores e usuários. Do ponto de vista metodológico, os argumentos aqui apresentados resultam de um estudo sobre a cidade de Fortaleza- $\mathrm{Ce}^{1}$, com base em dois

\footnotetext{
${ }^{1}$ A capital cearense tem $314,930 \mathrm{~km}^{2}$ de área e 2.591 .188 hab. (2015), dado que a coloca como a capital brasileira de maior densidade demográfica, com $7.786,4 \mathrm{hab} . / \mathrm{km}^{2}$.
} 


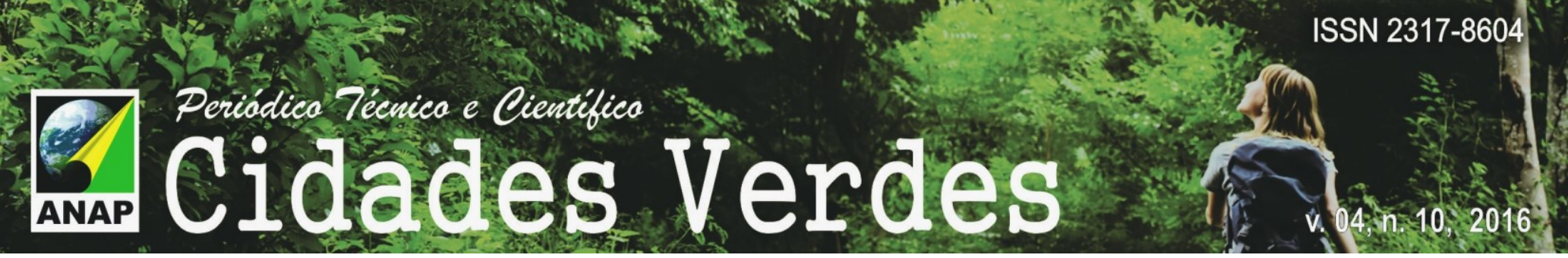

procedimentos: a análise empírica da divisão político-administrativa dos bairros e um exercício de intervenção urbanística realizado em um deles, o bairro Edson Queiroz.

Dadas as restrições impostas ao formato de um artigo científico, não será possível aprofundar em muitas das questões aqui arroladas, em especial, aquelas que se referem ao quadro histórico e aos instrumentos e ações associados ao ecobairro. Feita essa ressalva, admitiremos, em linhas gerais, que uma política urbana de ecobairros deve resultar não apenas do cruzamento de diferentes tradições teóricas e metodológicas, mas também de diferentes formas de interação entre a cultura e o conhecimento científico e não-científico. 0 ecobairro como política pública se esclarece em um cenário urbano no qual os atores sociais se definem e se identificam, não de uma maneira voluntarista, mas sobretudo através de uma relação, em um processo de experimentação e assimilação.

\section{A COMPETÊNCIA MUNICIPAL E O DESAFIO POLÍTICO-ECONÔMICO}

De início é preciso um acordo sobre o que vem a ser um bairro ecológico. A ausência de uma definição reconhecida e aceita aliada a uma apropriação aleatória do termo pode the conferir um sentido equivocado. Trata-se, afinal, de um território marcado por novas práticas de urbanismo, de ecologia urbana, de vida comunitária, ou um pouco disso tudo? Na literatura especializada, o termo ecobairro é cada vez mais empregado para designar uma unidade espacial urbana em que a ocupação e os usos do solo, a organização econômica e o modo de vida dos habitantes devem responder a princípios de respeito a longo prazo ao ambiente físico, social e econômico (CREPON, 2008; BARTON, 2000). O prefixo "eco" designa não apenas a integração do desenvolvimento sustentável a uma prática urbanística, mas também serve para sinalizar a vinculação da questão ambiental aos conceitos que ele acompanha.

Ao exercer suas competências constitucionais, o município poderá implementar uma política de ecobairros a partir de uma revisão do plano diretor e adequação de sua competência supletiva em matéria de meio ambiente para intervir e solucionar conflitos que the são pertinentes. Neste ponto, é preciso reconhecer que as Agendas 21 locais, apesar de não possuírem um vínculo jurídico com os documentos do planejamento urbano tradicional, constituem um inestimável aporte para se construir uma visão mais ampla do desenvolvimento urbano, abordando temas como: economia local, identidade local, patrimônio, ação social, esporte, etc.

É preciso ressaltar também que a dificuldade não é técnica. Ao contrário, a dificuldade é político-econômica. A maior parte dos espaços urbanizados são ineficazes em relação ao uso e ocupação do solo e medíocres em se tratando de qualidade urbana porque espelham os conflitos entre interesses especulativos e patrimonialistas que intensificam os riscos e neutralizam os serviços e mecanismos de proteção ao ambiente urbano (ASCERALD, 2001; LEVY, 2009).

No campo político, desconfia-se da eficiência dos atuais modelos de participação (MARICATO, 2012), sendo necessário avançar na concepção de novas formas interativas pelas quais instituições públicas, organizações privadas e comunidades partilham responsabilidades. No campo econômico, as áreas urbanas são impactadas por dinâmicas de fragmentação e 


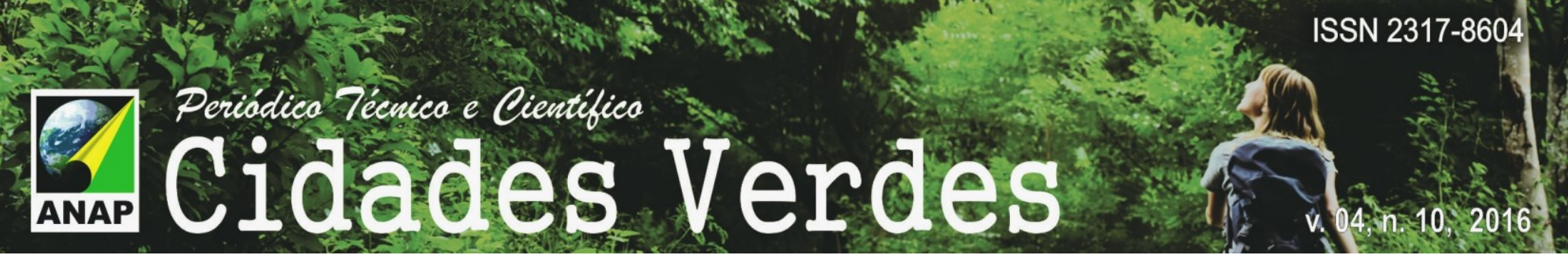

polarização resultantes de um processo complexo em que se conjugam as convergências locacionais do movimento migratório (imigração e migrações internas), as particularidades das políticas de habitação, as tendências de concentração do capital imobiliário e a seletividade dos investimentos em obras públicas.

Acreditamos que para superar essa dificuldade político-econômica será preciso colocar em debate os interesses que vinculam os moradores ao território através de novos arranjos de governança. Cada comunidade tem potencial para decidir sobre princípios que assegurem uma concepção de bairro adequada às novas exigências ambientais. Em tal perspectiva, o bairro deve ser encarado como uma multiplicidade de recortes que espelham os interesses divergentes dos atores econômicos e sociais, mas cuja combinação (ou confrontação) de todos esses recortes conduz a uma configuração local única. A compreensão dessa espacialização do sistema de atores é um trabalho necessário para praticar a gestão sustentável requerida ao ecobairro.

Em outras palavras, a cartografia do ecobairro se insere em um sistema não simplista resultante do confronto entre as espacialidades de cada grupo de atores, para a construção através da negociação - de um projeto de território comum. Todavia, é fundamental que esse sistema de atores tenha acesso a estudos e diagnósticos técnicos que produzam indicadores consistentes. Quais as ferramentas metodológicas necessárias para a construção desse inventário técnico? Não é possível discutir em poucas linhas esta questão complexa, embora seja possível afirmar que algumas das políticas e ações já experimentadas no país podem perfeitamente ser adaptadas para os ecobairros. Destacamos, por exemplo, o caso de políticas redistributivas como o orçamento participativo e o 'IQVU'

\section{ECO-ZONING E TIPOLOGIA DE ECOBAIRROS}

A importância do bairro como microunidade territorial do município está associada a aspectos socioculturais e administrativos, capazes de estabelecer um estreito vínculo de identidade da população com o espaço em que vive, e mais recentemente, de se consolidar como importante referência para a definição e gestão de políticas públicas. Essa tendência impõe o desafio de se identificar nos limites territoriais do bairro os parâmetros de um zoneamento funcional ecológico (ecological function zoning) ( $^{3}$ que se refere ao processo de divisão de áreas de acordo com as similaridades e distinções entre as características e sensibilidades ecoambientais e a importância dos eco-serviços (YANG, 2012). Um bom zoneamento funcional ecológico pode superar as lacunas do ordenamento do território tradicional que ignora a capacidade de transporte e a singularidade dos recursos ambientais locais.

No estudo do caso da cidade de Fortaleza, observamos que o processo de delimitação dos bairros sujeita-se tanto a decisões políticas arbitrárias como a resoluções técnicas sem critérios

\footnotetext{
${ }^{2} \mathrm{O}$ Índice de Qualidade de Vida Urbana (IQVU) é um índice multidimensional intraurbano que avalia e quantifica as desigualdades espaciais em termos de disponibilidade e acesso a bens e serviços urbanos, de modo a delimitar as áreas prioritárias para os investimentos públicos ( $\mathrm{PMBH}, 2014)$.

${ }^{3} \mathrm{~A}$ literatura especializada já sinaliza a urgência do eco-zoning, isto é, de se delimitar eco-territórios em diferentes escalas. Ver, p.ex, Yang (2012) e Abascal \& Bilbao (2016).
} 



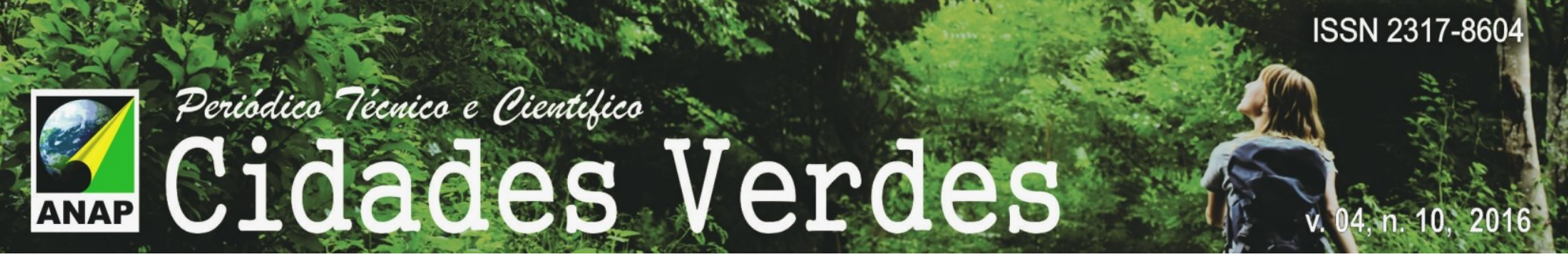

Do ponto de vista operacional, a ideia de ecobairro se caracteriza por ser um dispositivo que articula simultaneamente as diretrizes estratégicas do plano com as especificidades da programação projetual. Na perspectiva do plano o ecobairro deve ser presumido como parte integrante da abordagem da cidade, respondendo às mesmas problemáticas (saneamento, transportes, emprego, etc.). No âmbito do projeto, o objetivo é estruturar uma trama de fundo denso, diversificada e interconectada, respeitando as condições ambientais para a gestão do ambiente construído. Visto como política pública, o ecobairro seria, portanto, um ponto de ancoragem entre plano e projeto, inscrevendo-se em uma abordagem técnica de melhoria contínua das infraestruturas físicas e cívicas, agregando as boas práticas urbanas acordadas em uma organização mais ampla de mobilização política.

\subsection{OS PLANOS DE ECOBAIRRO}

Os planos de bairro já não são alheios à realidade urbana brasileira. Com objetivos semelhantes, algumas das nossas grandes cidades vêm desenvolvendo estratégias para posicionar e qualificar o bairro como escala de base da estruturação urbana ${ }^{5}$. 0 fato irrefutável é que o crescimento urbano impôs a necessidade de descentralização dos sistemas de planejamento e gestão através da adoção de novos recortes espaciais para melhorar o funcionamento da macroestrutura urbana. Neste tipo de abordagem, o que importa é a criação e aplicação de instrumentos que regulem a policentralidade intra-urbana, a partir do controle dos usos e ocupação do solo, da implantação de equipamentos públicos ou ainda das redes de mobilidade e acessibilidade.

Avançando nesta direção e seguindo os ensinamentos de DUPUY (1991), a recomposição da cidade em termos de planos para ecobairros deve considerar que os nós contam tanto que as zonas funcionais, as conexões tanto ou mais que as fronteiras, o tempo tanto ou mais que o espaço. Certamente se faz necessário que esses planos se ajustem às estratégias gerais estabelecidas no Plano Diretor Municipal, mas se deve oferecer a eles a oportunidade de alinhar medidas diferenciadas de modo a garantir coerência e precisão no espaço intrabairro. O tempo deverá mostrar se as esperadas agilidade e efetividade de ações concretas para o bairro não distorçam a essência do plano diretor que, naturalmente, deve ser sempre a matriz de ordenamento territorial.

O plano de ecobairro é, portanto, o documento destinado à aplicação de novos dispositivos urbanísticos, abrindo um campo de possibilidades criativas e experimentações ajustadas em termos de desenvolvimento sustentável. Tal perspectiva indica que as normas de usos e ocupação do solo não podem mais se contrapor à qualidade ambiental urbana, mas contribuir decisivamente para alcançar melhores performances energéticas e ambientais. Em quaisquer circunstâncias, os instrumentos dispostos nos planos de ecobairros devem atender a pelo menos duas finalidades: elevar o nível de controle fundiário, através de parâmetros mais

\footnotetext{
${ }^{5}$ No mais recente período de revisão de planos diretores, o bairro ganhou força como escala de estruturação urbana quando algumas metrópoles (São Paulo, Porto Alegre, Curitiba...) adotaram diretrizes e normas para a elaboração de 'planos de desenvolvimento de bairros' e 'planos de vizinhança'.
} 


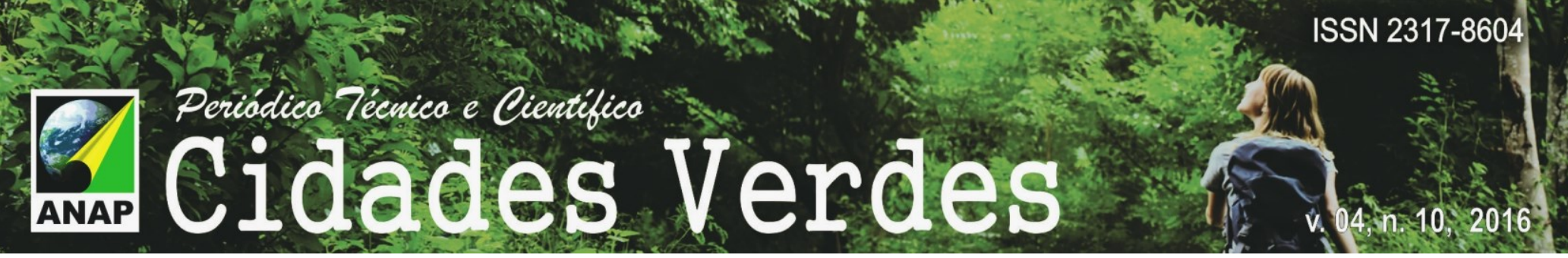

precisos e adaptados às singularidades de cada bairro; e fixar os limites para o crescimento horizontal e vertical, através de esquemas de coerência morfo-tipológica. Independente do dispositivo adotado, é importante insistir no seu monitoriamento periódico - através de um plano de inspeção ambiental - para o controle de sua adequabilidade ao ecobairro.

Apenas para citar alguns exemplos, destacamos os seguintes instrumentos em discussão no país que poderiam compor uma agenda de planos de ecobairros:

- As "operações urbanas simplificadas" (focadas em áreas reduzidas), que retêm uma legislação ágil possibilitando a intervenção em um conjunto de quarteirões para uso de área pública, aumentando o potencial construtivo e exigindo do empreendedor benfeitorias diretas conforme o caso (LEITE, 2016);

- As "operações urbanas concentradas" (destinadas a um setor específico), que possibilita a implementação, por exemplo, de habitação de interesse social com usos mistos e equipamentos urbanos conjugados (LEITE, 2016);

- O "fator verde", que se caracteriza como um parâmetro de medidas urbanísticas adaptado aos condicionantes do ecossistema urbano local, na busca de equalizar os impactos da ocupação e uso do solo, e cujo cálculo leva em consideração a biodiversidade e a adaptação climática (PREFEITURA DE FORTALEZA, 2012).

\subsection{OS PROJETOS DE ESTRUTURAÇÃO URBANA}

Os projetos de estruturação urbana devem ser articulados e conexos aos planos de ecobairro. O objetivo é complementar o urbanismo de normas com um urbanismo de projeto, de modo a alcançar um melhor condicionamento ambiental. Trata-se essencialmente de um mecanismo contra a lógica da rigidez dos regulamentos, que conduz a uma certa estandartização na produção dos espaços urbanos, e a favor de uma sistematização fundada na articulação de um conjunto de ações programáticas destinadas a assegurar o bom desempenho do ambiente construído.

Em sua concepção, esses projetos estruturantes demandam um saber distintivo sobre o processo de transformação do bairro, de modo a estabelecer uma mediação consistente entre as diferentes escalas (do lote, do quarteirão, dos espaços livres). A sua formulação, entretanto, deve considerar as contribuições de múltiplas competências de expertise (economistas, geógrafos, sociológos, antropólogos, cientistas políticos, etc.) e não unicamente as questões de organização espacial, pois eles se aplicam em uma realidade em que as formas materiais e as formas sociais são ligadas por relações complexas. Podemos afirmar que eles comportam uma pensée de relation, pois constituem uma conexão entre o espaço e o tempo da cidade.

Como princípio, um projeto estruturante de ecobairros não deve ser concebido para um único canteiro de obras, mas acompanhar as dinâmicas de mutação ao longo do tempo, e sendo assim, ele não responde à lógica das intervenções de urgência. Vale também dizer que, neste caso, a ação projetual se distancia necessariamente daquelas experiências que se apoiam em estratégias de remodelação ou revitalização urbana, com efeitos previsíveis de expulsão dos antigos moradores e consequente gentrificação do lugar. Para efeito de demonstração, 


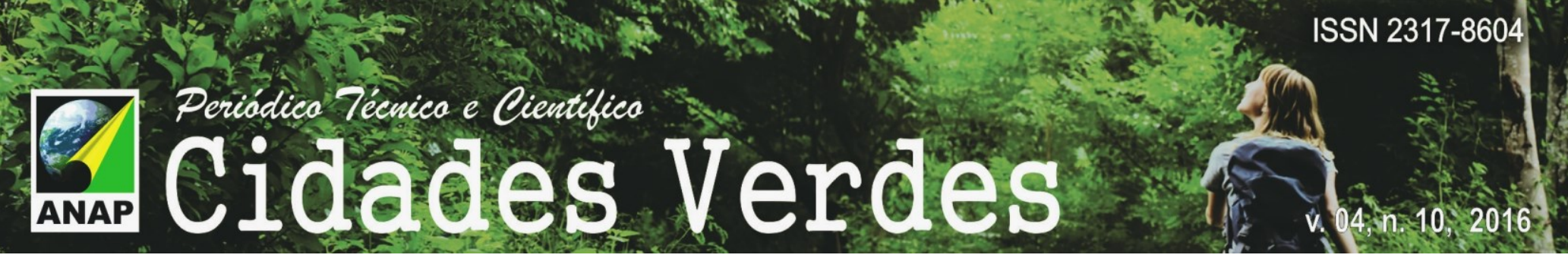

reunimos uma lista de componentes constituintes para a ação programática de projetos estruturantes de ecobairros, distribuídos em quatro domínios de ação (ver Quadro 2). Não se trata, evidentemente, de uma lista definitiva ou exaustiva, podendo ser objeto de adequações e complementações conforme as exigências de cada situação.

\subsection{UM ESTUDO DE CASO: O BAIRRO EDSON QUEIROZ}

Com base no estudo do bairro Edson Queiroz, situado em uma área de importância estratégia para a sustentabilidade da porção leste da cidade de Fortaleza, experimentamos algumas das soluções comentadas no presente texto ${ }^{6}$. Atualmente, este bairro soma uma área de 1.601 ha, situando-se entre os mais extensos da cidade, mas com uma população residente de 22.210 hab. (2010), dado que o coloca entre aqueles de baixa densidade residencial (12,61 hab/ha). E, ainda assim, ele agrega muitos dos desafios que se espera de uma política de ecobairros.

O que antes era uma região ocupada por extensos manguezais associados à dinâmica hídrica do baixo rio Cocó e ocupada predominantemente por sítios e chácaras, transformou-se, a partir da última década do século passado, em uma área de ocupação desordenada e incompleta, trazendo consigo graves desequilíbrios socioambientais denunciados em seu baixo IDH (0,350). O Edson Queiroz é um mosaico de desigualdades sociais, econômicas e morfológicas, onde convivem lado a lado comunidades de baixa renda, condomínios residenciais fechados, grandes equipamentos comerciais e institucionais e áreas de proteção ambiental. $\mathrm{O}$ grande número de lotes ainda não ocupados revela um estoque especulativo à espera de valorização fundiária.

\footnotetext{
${ }^{6}$ As propostas aqui apresentadas foram concebidas por equipes de alunos de graduação em Arquitetura e Urbanismo, no âmbito de uma disciplina de Projeto Urbanístico.
} 


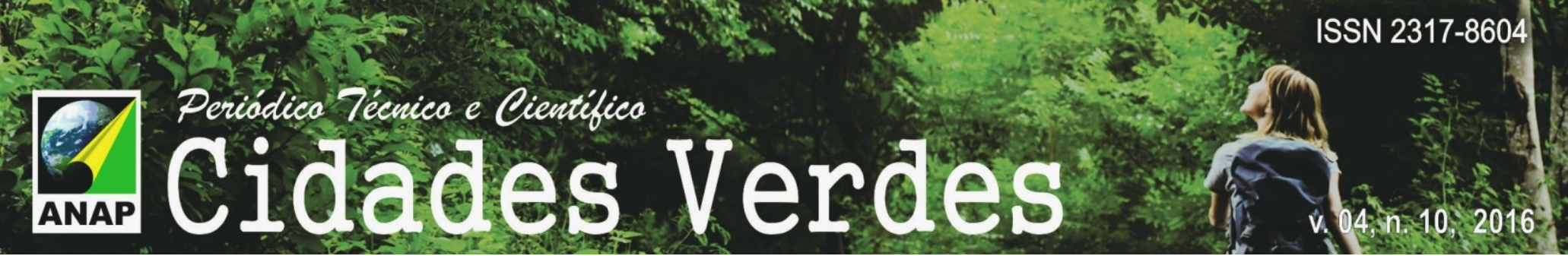

bairro. Ainda que sinalizem uma finalidade preservacionista, do modo como se encontram, as normas urbanísticas fixadas por essas zonas não são adequadas ao enfrentamento dos conflitos e contradições decorrentes das pressões da urbanização sobre o ambiente natural. 0 diagnóstico da situação revela que o processo de ocupação, atualmente concentrado nas porções oeste e sul, provoca diferentes dinâmicas internas (morfológicas, sociais e econômicas) que induzem a duas tendências: a ocorrência de um mosaico - mais realista e preciso -, de pelo menos oito setores sóciomorfológicos, sendo cinco deles situadas na zona ocupação moderada (verFigura 3-A); e a ausência de uma harmonização entre a legislação de uso e ocupação do solo e a futura consolidação da estrutura viária (ver Figura 3-B).

Figura 2: Macrozeamento urbano e zoneamento ambiental incidentes no bairro Edson Queiroz.

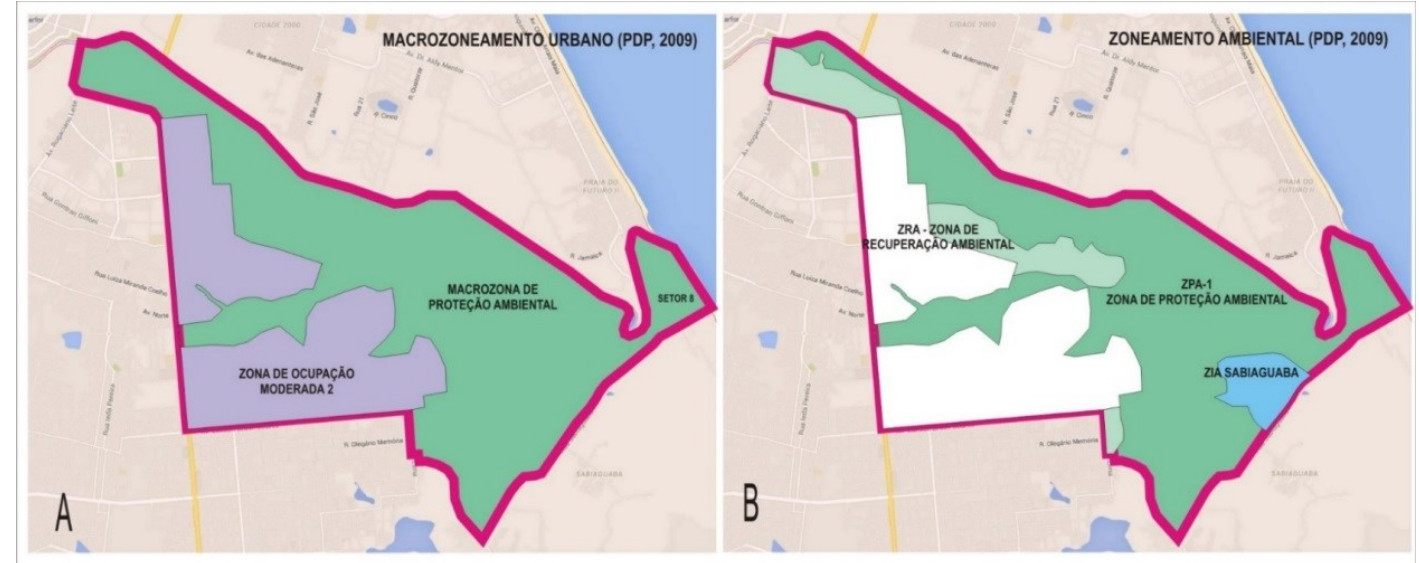

Fonte: Prefeitura Municipal de Fortaleza. Plano Diretor Participativo do Município de Fortaleza, 2009.

Figura 3: Identificação dos setores sócio-morfológicos e da estruturação viária atual do bairro Edson Queiroz.
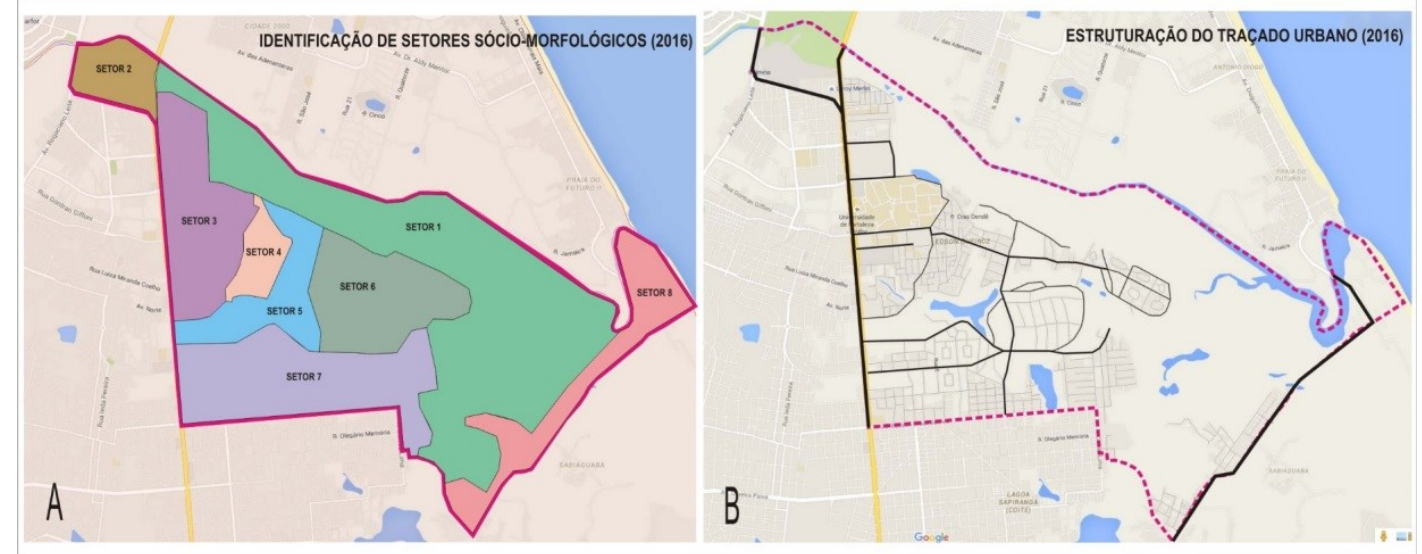

Fonte: Estudo e análise elaborados por alunos do curso de graduação em Arquitetura e Urbanismo. 2016.

Transformar o Edson Queiroz em ecobairro evoca diversas possibilidades estratégicas. Destacamos abaixo uma breve síntese de uma proposta de plano e projeto estruturante para este bairro concebida no contexto de um exercício acadêmico.

Primeiramente, um plano de ecobairro poderia considerar o pressuposto de uma redefinição dos atuais limites oficiais, excluindo a macrozona de proteção ambiental e concentrando-se essencialmente na zona de ocupação moderada. Em seguida, ele estabeleceria uma nova 


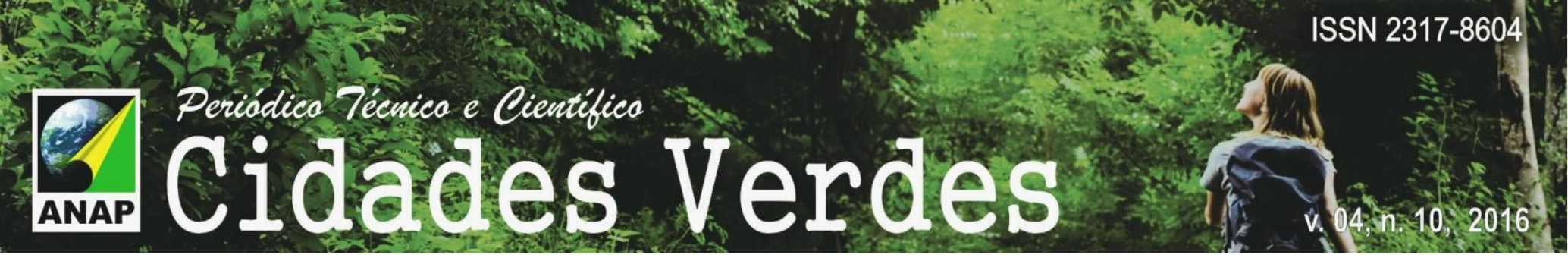

partição do zoneamento intrabairro para ajustar as pressões relacionadas ao uso e ocupação do solo. Isso significa dizer que, no lugar de uma única zona de ocupação moderada, seria possível adotar uma divisão por setores com densidades construtivas diferenciadas de acordo com a vocação sóciofuncional de cada setor e sua posição geográfica e relação sinérgica com o ecossistema local. Simultaneamente, articula-se a zona de proteção ambiental com a consolidação de uma rede de espaços livres destinada à fruição pública urbana.

Complementarmente, um projeto estruturante para o ecobairro adotaria a medida de interromper uma futura conexão viária no sentido leste-oeste, evitando, assim, o um avanço da urbanização sobre a ZPA e o conseguente incremento exponencial do tráfego de passagem (ver Figura 4-A). Em seguida, a zona de ocupação moderada seria submetida a uma operação de composição urbana, uma intervenção de desenho urbano que articula e costura os diversos fragmentos sóciofuncionais em torno de uma rede de infraestrutura verde. $O$ tratamento inclusivo das zonas de interesse social, a criação de um centro de bairro e a distribuição de uma rede de equipamentos públicos complementam e dão um novo caráter ao ecobairro (ver Figura 4-B).

Figura 4: Uma proposta de plano e projetos para o bairro Edson Queiroz.

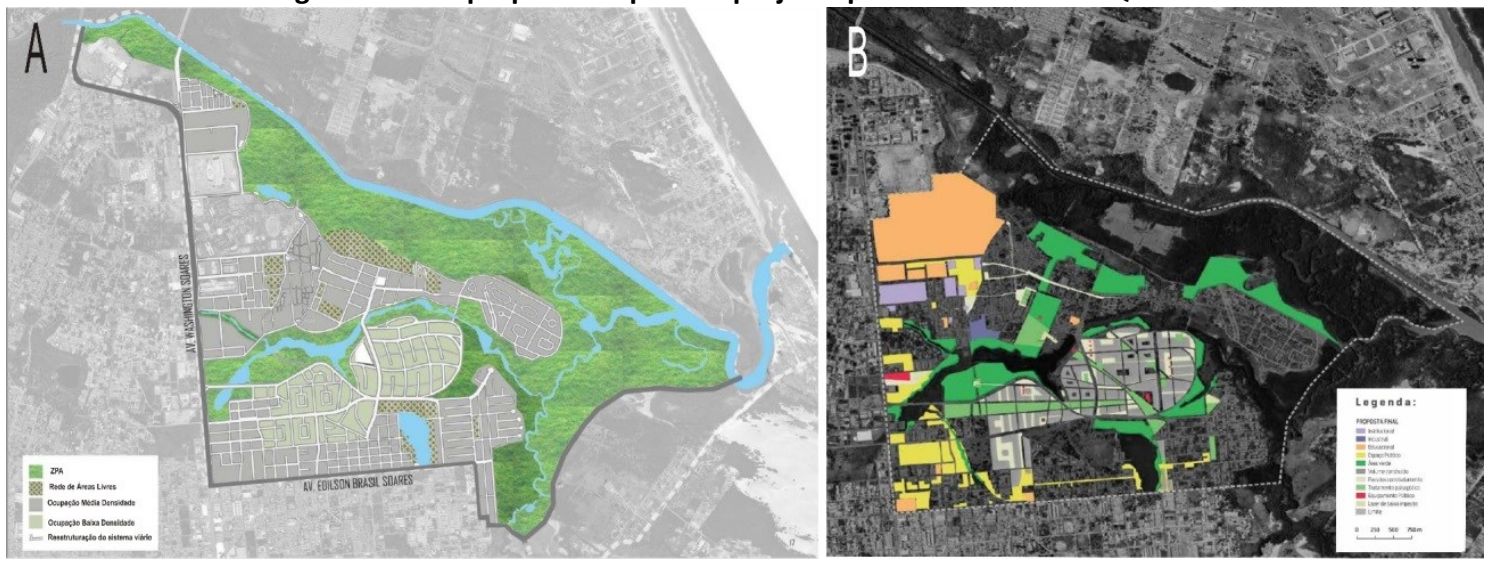

Fonte: Trabalho elaborado por equipe de alunos de graduação em Arquitetura e Urbanismo. 2016.

\section{CONCLUSÃO}

Como se pode observar nas anotações aqui apresentadas, um certo número de pré-requisitos não difere em nada daquelas políticas públicas que guardem ambições em termos de desenvolvimento sustentável. Mas no cenário brasileiro, a experiência de uma política urbana de ecobairros pode significar um passo à frente, na medida em que sinaliza o fortalecimento do controle social e a diminuição das desigualdades intraurbanas, atuando como escala urbana de ações redistributivas. Na pior das hipóteses, talvez sirva como uma declaração crítica de racionalidade local frente aos embates resultantes da ação neoliberal hegemônica, de reação dos atores excluídos e de adoção de medidas urbanísticas de compensação social e ambiental. Por requerer uma nova visão da ação pública sobre a cidade e, em especial, novos arranjos de governança, um ecobairro levaria em conta a vontade e o engajamento dos cidadãos no que 


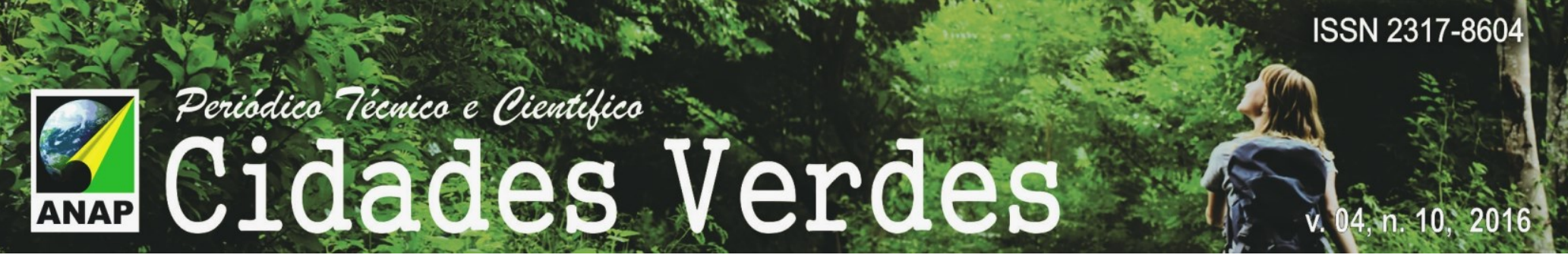

essa "energia social" pode ter de melhor. Além disso, na ideia de ecobairro estaria embutida a generalização do raciocínio do custo total, uma abordagem em que a diferenciação das condições locais prevalece nas decisões socioeconômicas. Sem a radicalização dessa crítica, todas as propostas formais de sustentabilidade urbana, por mais alternativas que se julguem, tenderão a produzir o mesmo efeito de ocultação e descrédito.

\section{REFERÊNCIAS BIBLIOGRÁFICAS}

ABASCAL, Eunice H.S. e BILBAO, Carlos A. Ecorregiões e gestão do planejamento urbano-regional. Desafios da aplicação da técnica de ponderação na região metropolitana de Medellín. In Arquitextos, 193.06, ano 17, jun. 2016. Ver em http://www.vitruvius.com.br/revistas/read/arquitextos/17.193/6109. Acesso em 12/07/2016.

AJA, Agustín Hernández, VALORIA, Isabel V. \& VIANA-CÁRDENAS, Carlos V. Ecobarrios para ciudades mejores. In Ciudad y Territorio. Estudios Territoriales, XLI (161-162), 2009, p.543-558.

ASCERALD, Henri. A duração das cidades: sustentabilidade e risco nas políticas urbanas. Rio de Janeiro: DP\&A, 2001.

ASCERALD, Henri. Desregulamentação, contradições espaciais e sustentabilidade urbana. In Anais XI Enanpur, Salvador-Ba, 2005, p. 01-19.

BENNETT, R. EcoDISTRICTS. Framework Concept for Metro Portland. Portland: Portland+Oregon Sustainability Institute. http://oregonsustainabilitycenter.files.wordpress.com/2009/05/ecodistrictsframework-plan-4-09.pdf. 2009. Acesso em 20/06/2016.

BARTON, Hugh. Sustainable communities. The potential for econeighbourhoods. London: Earthscan, 2000.

CAMPOS FILHO, C.M. Cidades brasileiras: seu controle ou o caos. O que os cidadãos devem fazer para a humanização das cidades no Brasil. São Paulo: Nobel, 1989.

CAMPOS FILHO, C.M. Reinvente seu bairro. Caminhos para você participar do planejamento de sua cidade. São Paulo: Ed. 34, 2003.

CREPON, E. Concevoir um écoquartier. In Premier Plan, n¹6, janvier-juin, 2008.

DUPUY, Gabriel. L’urbanisme des réseaux. Théories et méthodes. Paris: Armand Colin, 1991.

FORTALEZA (Prefeitura Municipal). Fator verde Sabiaguaba. Fortaleza: PMF/Paper, 2012.

GOMES, R.A. Ecobairro. Um conceito para o desenho urbano. Dissertação de Mestrado em Planeamento do Território - Ordenamento da Cidade. Aveiro-Portugal: Universidade de Aveiro, 2009l.

GRAHAM, Stephen and MARVIN, Simon. Splintering Urbanism. London: Routledge, 2001.

LANG, Jon. Urban Design: a typology of procedures and products. Amsterdam: Elsevier, 2005.

LEFEBVRE, Henri. Quartier et vie de quartier. In Cahiers de I’IAURP, vol.7, 1967.

LEITE, Carlos. Instrumentos urbanos inovadores. In ARCOweb, https://arcoweb.com.br/, publicado em 24/05/2016.

LEVY, Albert. Quel urbanisme face aux mutations de la société post-industrielle?. In Esprit, vol II, nov. 2006, p.61-75.

LEVY, Albert. La « ville durable ». Paradoxes et limites d'une doctrine d’urbanisme emergente. In Esprit, no12, déc. 2009, p.136-153. 


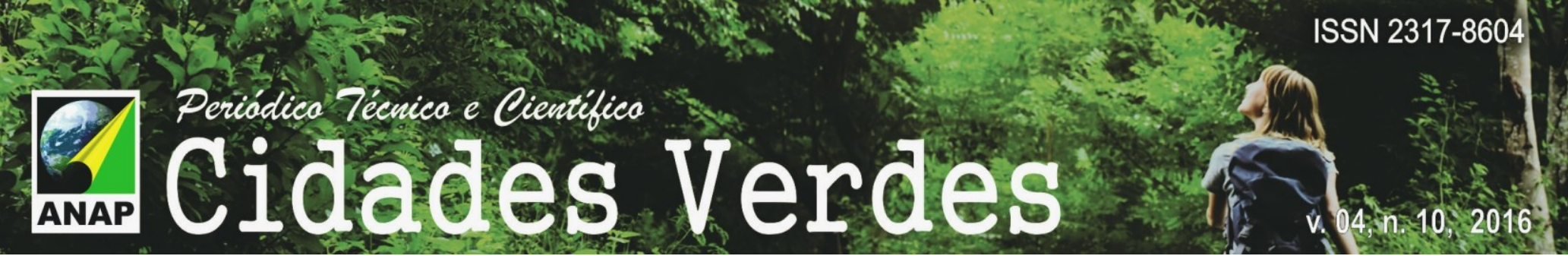

MARICATO, Ermínia. O impasse da política urbana no Brasil. Petrópolis-RJ: Vozes, 2012.

PAQUOT. T. L'écologie urbaine peut-elle sauver la ville? Marseille-Fr: Conferência, fevereiro de 2013. In www.marseilledelavillealametropole.com. Acesso em 10/05/2016.

POUPINOT, P. Ecoquartiers. Quartiers de rêve? Utopies et realité. Oise-la-Vallée-Fr: Agence d’Urbanisme, 2011.

PMBH. Relatório geral sobre o cálculo do IQVU-BH. Belo Horizonte: SMPOI, 2014.

RODRIGUEZ, M.E.P. Planos urbanos locais. Definição concreta para a mobilidade e qualidade ambiental urbanas. Tese de doutorado em Arquitetura e Urbanismo, FAUUSP. São Paulo: FAUUSP, 2003.

ROMERO, Marta A.B. e FERNANDES, Júlia T. (orgs.). Reabilita. Reabilitação Ambiental Sustentável Arquitetônica e Urbanística. Registro de Curso de Especialização a Distância. Brasília: UnB, 2015.

SAHEB, Y. Analyse critique des quarties durables. La Fabrique de la Cité. 2008. Ver em http://www.lafabriquedelacite.com/. Acesso 20/07/2016.

SOUAMI, Taoufik. Écoquartiers. Secrets de fabrication. Analyse critique d'exemples européens. Paris: Ed. Les Carnets de l'info, 2009.

YANG, Zhifeng (ed.). Eco-Cities: A Planning Guide. Beijing: CRC Press, 2012. 